\title{
Penile Torsion Correction by Diagonal Corporal Plication Sutures
}

\author{
Brent W. Snow \\ Division of Urology, University of Utah, Salt Lake City, Utah, USA
}

\begin{abstract}
Penile torsion is commonly encountered. It can be caused by skin and dartos adherence or Buck's fascia attachments. The authors suggest a new surgical approach to solve both problems. If Buck's fascia involvement is demonstrated by artificial erection then a new diagonal corporal plication suture is described to effectively solve this problem.
\end{abstract}

Key words: penis; sutures; male urologic surgical procedure

Int Braz J Urol. 2009; 35: 56-9

\section{INTRODUCTION}

Penile torsion in childhood is usually in the counterclockwise direction, if the physician is facing the patient. If the penile torsion is less than 20-30 degrees, surgical correction is not considered. The etiology of torsion of the penis has been thought to be due to skin and dartos attachments and yet others suggest involvement of Buck's fascia. When penile torsion correction is appropriate, various repairs have been considered: 1) penile shaft skin rotation (1);2) suturing the tunica albuginea to the periosteum of the pubis (2) or 3) dorsal dartos flap rotation (3); 4) Nesbit plication (4) or u-shaped plicating sutures (5). A new technique is presented to correct penile torsion that is persistent after the skin had been completely degloved and an artificial erection has demonstrated persistence of the torsion.

\section{SURGICAL TECHNIQUE}

The skin of the penis is degloved to the base of the penis and an artificial erection is performed.
If the penile torsion is resolved with degloving of the shaft skin, the skin is over-rotated to allow the penis to be straight in the flaccid state to complete the repair.

If the artificial erection shows persistence of the penile torsion, an inverted permanent braided 4-0 diagonal plicating suture is taken parallel to the neurovascular bundle on the right corporal cavernous body and the opposite half of the suture is taken parallel to the neurovascular bundle more proximally on the left corporal cavernous body (Figure-1) (presuming the normal counterclockwise rotation of the penis). When this diagonal plicating suture is tied protecting the neurovascular bundle, the artificial erection is repeated and this is usually sufficient to correct the penile torsion. If the torsion persists, additional diagonal plicating sutures may be used. The permanent sutures will last long enough for scarring to take place before the sutures will lose their tension. An incision in the tunica albuginea on each corpus beside the plicating sutures can be used to allow fresh cut edges to permanently heal the plication if desired. 


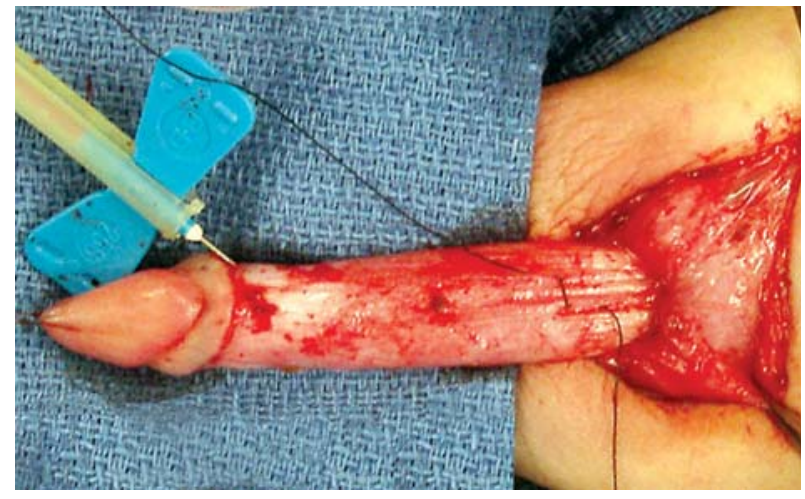

Figure 1 - Shows the diagonal corporal plication suture, which is more distal on the right corpora and more proximal on the left corpora to correct the most common direction of penile torsion. Once the suture is tied, the artificial erection will be repeated to make certain that the torsion has been entirely corrected.

\section{COMMENTS}

With this recommended technique of degloving first and performing an artificial erection if only skin and dartos are involved with the torsion, the common over-rotation of the skin can be used to complete the penile detorsion procedure. If the erections demonstrate persistent penile torsion, this

\section{Correspondence address:}

Dr. Brent W. Snow

Division of Urology, University of Utah

100 N Mario Capecchi Drive, Ste. 2200

Salt Lake City, Utah, 84113-1100, USA

E-mail: brent.snow@hsc.utah.edu

\section{EDITORIAL COMMENT}

Although penile torsion is not frequent in childhood, it is not so rare. Each individual urologist will face a few cases of torsion during the life of their practice. Despite the most common technique used diagonal corporal plication suture is much easier to perform than suturing the corpora to the periosteum of the pubis, which requires much more dissection, and has been very effective.

\section{CONFLICT OF INTEREST}

None declared.

\section{REFERENCES}

1. Bar-Yosef Y, Binyamini J, Matzkin H, Ben-Chaim J: Degloving and realignment--simple repair of isolated penile torsion. Urology. 2007; 69: 369-71.

2. Zhou L, Mei H, Hwang AH, Xie HW, Hardy BE: Penile torsion repair by suturing tunica albuginea to the pubic periosteum. J Pediatr Surg. 2006; 41: e7-9.

3. Fisher C, Park M: Penile torsion repair using dorsal dartos flap rotation. J Urol. 2004; 171: 1903-4.

4. Slawin KM, Nagler HM: Treatment of congenital penile curvature with penile torsion: a new twist. J Urol. 1992; 147: 152-4.

5. Hsieh JT, Wong WY, Chen J, Chang HJ, Liu SP: Congenital isolated penile torsion in adults: untwist with plication. Urology. 2002; 59: 438-40.

Accepted after revision: October 30, 2008

to repair this defect is the modified Nesbit plication. I believe in everyday practice we all perform this procedure as mentioned by the authors. On the other hand, because young men can present very strong 
erections I in fact prefer to use an inverted permanent braided 2-0 suture.

It is worth remembering that a simple procedure as described in this article can really help a number of young men who have often their quality of life severely affected by penile torsion.

Dr. Joaquim A. Claro Division of Urology University of Sao Paulo, USP Sao Paulo, Brazil E-mail:joaquimclaro@hotmail.com

\section{EDITORIAL COMMENT}

This is another reliable technique for correction of penile torsion. I am concerned that the sutures are tied over the neurovascular bundle with the consequent strangulation. A procedure around this is the mobilization of the bundle at the desired site of plication and placing the suture beneath the bundle. In addition, diagonal sutures at different vertical levels across the midline may result in shortening especially in cases of severe torsion requiring multiple sutures. In this context, it is my opinion that the "diagonal corporal placation sutures" should be the last resort if other shortening-free techniques prove short of full correction, not merely skin over-rotation (a step within the author's procedure) but also dorsal dartos flaps.

\author{
Dr. O. Shaeer \\ Department of Andrology \\ Faculty of Medicine, Cairo University \\ Cairo, Egypt \\ E-mail:dr-osama@link.net
}

\section{EDITORIAL COMMENT}

The true incidence of penile torsion, which is not a very common deformity, is not known. Penile torsion can be encountered independently or in association with other penile and urethral malformations, such as chordee and hypospadias (1). Several relatively old techniques have been described in the literature for correcting penile torsion, including degloving the penis and reattaching the skin (2) incising the base of the penis (3) and removing angular ellipses of corporeal tissue with subsequent plication, in addition to the techniques described in the literature of the current paper. However, these procedures have not been very effective in severe penile torsion cases or associated with significant operative morbidity. In the current report author described a novel technique to correct penile torsion that is persistent after the skin had been completely degloved and an artificial erection has demonstrated persistence of the torsion. The author has demonstrated that diagonal corporal plication suture is much easier to be performed than suturing the corpora to the periosteum of the pubis, which requires much more dissection, and has been very effective. Although the current technique is promising and has some potential, however long term data on a larger number of patients is required to popularize this technique. 


\section{Penile Torsion Correction}

\section{REFERENCES}

1. Redman JF, Bissada NK: One-stage correction of chordee and 180-degree penile torsion. Urology. 1976; 7: 632-3.

2. Azmy A, Eckstein HB: Surgical correction of torsion of the penis. Br J Urol. 1981; 53: 378-9.
3. Culp OS: Struggles and triumphs with hypospadias and associated anomalies: review of 400 cases. J Urol. 1966; 96: 339-51.

Dr. Ahmed I. El-Sakka Andrology Clinic, Diabetic Centre Al-Noor Specialist Hospital, PO Box 6251 Makkah, Saudi Arabia E-mail: aielsakka@yahoo.com 